\title{
PARKES CENTENARY MEMORIAL LECTURE* "SERVICE, COMMUNITY AND HEALTH"
}

\author{
Dr. WILFRID G. HARDING, F.R.C.P., P.F.C.M. \\ President, Faculty of Community Medicine of the Royal Colleges of Physicians of the \\ United Kingdom
}

THE invitation to contribute to this historic occasion is for me a unique distinction in more than one way. I had the honour of following in Dr. Parkes' footsteps at University College and University College Hospital as a medical student, and I retain my close association with that hospital. I must admit that I remember Parkes' marble bust in the medical school library from my days as an undergraduate, but that the name meant nothing to me until much later, during my Diploma in Public Health course at the London School of Hygiene, I came across a biographical note linked with his name on the frieze of the building and soon after read about him in Simon's English Sanitary Institutions and in Cecil Woodham-Smith's biography of Florence Nightingale.

The invitation to deliver this lecture has given me a somewhat closer acquaintance with this outstanding man who was so far ahead of his time.

Your Director-General was speculating about the title of my address "Service, Community and Health". The title suggested itself for several reasons and perhaps primarily from browsing through Parkes' works.

Throughout his writings and especially in his Manual of Practical Hygiene ${ }^{1}$ he exhibits a close concern with the promotion of health of the Service Community, and in the introduction of the first edition, he writes:

"In many cases, again, the employer of labour finds that, by proper sanitary care of his men, he reaps at once an advantage in better and more zealous work, in fewer interruptions from ill health, etc., so that his apparent outlay is more than compensated.

This is shown in the strongest light by the army. The State employs a large number of men, whom it places under its own social and sanitary conditions. It removes from them much of the self-control with regard to hygiene rules which other men possess; and is therefore bound by every principle of honest and fair contract to see that these men are in no way injured by its system. But more than this: it is as much bound by its self-interest. It has been proved over and over again that nothing is so costly in all ways as disease, and that nothing is so remunerative which augments health, and in doing so the amount and value of the work done".

Is it not remarkable how true this last sentence, written well over a century ago, rings in the light of the Government's two consultative documents on prevention ${ }^{2}$ on priorities ${ }^{3}$ which were published during the last few weeks?

Parkes returns to the theme of prevention in 1851 in his introductory lecture to medical students of University College ${ }^{4}$-and, of course, on many other occasions.

I have spoken about my historic link with Parkes through the common base of our medical school. But my debt to him more indirectly as the founder of Army Health as we know it now and more directly to the Corps which invited me to address you today goes much deeper, and this explains and, I hope, excuses if a good deal of what I am

* Lecture given at the Royal Army Medical College, Millbank on 5th May 1976. 
going to say is based on personal experience gained during my brief service in the Corps. I attribute my input into Community Medicine, both in practice and in one's contribution to the Faculty of Community Medicine, very largely to the teaching which I received from the Army and to the formative influence which the R.A.M.C. has had on my personal and professional life.

Parkes' manual of practical hygiene and especially its concluding chapters on foreign service say much about the capacity of the soldier to adapt to strange service conditions. The environment in which we found ourselves in Germany during the concluding stages of the last War, and after, and the tasks with which we were then faced certainly were hardly covered by service manuals or War Office instructions. They provided challenges which went far beyond those covered by established medical and hygiene teaching, and posed serious organisational and also ethical problems. Not only were the occupying forces faced with grave immediate public health problems, especially in a unique aggregation of urban communities such as the Ruhr where I was to work, in which two-thirds of the houses in just one town, Essen, were totally destroyed and most of the remaining ones only partially habitable, together with over 2,000 sewer breaks and 4,000 breaks in the water mains in that town alone.

But alongside the need to restore tolerable environmental conditions and to deal with major infectious disease hazards such as the enteric diseases, typhus which was so effectively contained by the policy of the two cordons sanitaires along the rivers Elbe and Rhine, and diphtheria of which there were in 1946 over 10,000 cases in my Ruhr population of $3,500,000$, alongside these dramatic problems there was equally important and perhaps not quite as directly related to military duty and medical experience, the need to get German industry and especially the mining of Ruhr coal going again. My first major assignment in Community Medicine arose directly out of this; the Corps Command in which I served as a staff learner and medical officer was concerned about alleged improper medical certification in respect of both direction of new manpower into the mines and of medical absenteeism of miners already in employment. The Labour Priorities Board set up at Corps HQ asked for an attachment of 15 British medical officers to check medical certification in the Ruhr mines.

The D.D.M.S., a man with the wisdom and tolerance which I came to admire again and again in the regulars of those days, and ever since, ordered me, a very raw Captain and staff learner, to investigate and to report.

After a rapid but fairly detailed survey I found surprisingly low rates of rejection of newly directed entrants by the German medical referees, and equally surprisingly low rates of medical absenteeism, both in absolute terms and also in comparison with experience in mines in the United Kingdom, especially in the light of the environmental and personal health problems in this area of devastation and dejection. Comparison with contemporary statistics from the United Kingdom (with all the necessary reservations about the limited comparability of such data) showed that whilst there were wide variations in certification between individual mines, heavy-handed measures such as medical check procedures carried out by medical officers of the occupying force were certainly not indicated and could well have proved counter-productive in terms of resentment and even sabotage. Instead, of the $12 \mathrm{M}$.Os we recommended a simple statistical return system for rejection of new entrants on medical grounds and a scheme of double-checking of medical rejections by German doctors, and for medical absenteeism 
a similar check procedure by German local medical boards. The Brigadier's final recommendation was that instead of the 12 British M.Os asked for one British doctor, preferably a German linguist, should be permanently charged with the medical oversight of the mining population in the Ruhr and give advice on the medical oversight of housing, diet and working hours as well as on medical manpower problems, but even this much less expensive alternative was never implemented in that form.

In relation to my theme today, the incident confirms the need for epidemiological investigation, however simple, of the existence and the size of health problems in a community before services are established - and also the capacity of your Service to adapt to unfamiliar problems.

In terms of the Faculty's present-day specialist training programme I would by then have been at the stage of the early specialist trainee,--just about four years after qualifying. In that context my first exercise in community medicine could perhaps be counted as a small project during the early stage of specialist training - the field work took just about the same time as one of our training modules, 2 to 3 weeks, to complete, and the writing up two or three days.

My first independent R.A.M.C. assignment was to take charge of the German health services for a population of over 1.5 million, and a little later for the whole Ruhr, with a population of $3,500,000$.

From my records I have chosen just one episode. It does not reflect anything like the dramatic experiences and original work of Parkes during his three years of Army service in India immediately after he qualified and from which stemmed his first two papers in the Madras Medical Journal of 1843 and 1844, and his two monographs on dysentery and hepatitis, and on cholera. As I have said, we in the Ruhr also had major infectious disease problems, but nothing can probably better demonstrate the opportunities with which one was then presented, in terms of health care planning and of resource exploitation than our local effort in the Ruhr to control scabies.

In the post-war environment, with tremendous over-crowding, caused by massive air-bombardment and aggravated by the influx of refugees from the East, scabies was not just an irritating nuisance, but a significant cause of industrial absenteeism. Checks in schools showed an over-all infestation rate of more than 10 per cent, rising to 32 per cent in some districts, and this probably reflected the prevalence in the population as a whole.

I made the disease notifiable, although I realised, of course, that probably only a very small proportion of the sufferers were consulting their doctors, for the simple reason that it was common knowledge that there was no effective treatment to be had in Germany at that time. The only application which was freely available was a lotion called N.15, which contained benzoic acid, not as a benzoate, in an alcoholic solution. It was highly irritant and not at all effective, but widely sold, because it was simple to re-distil the alcoholic solvent. Although notified cases obviously represented only a small part of the total, we had as many as 2,000 weekly notifications in the peak period. Importation of drugs was out of the question and self-help the only possible answer.

I had in my district the large Buna factory, the largest synthetic rubber plant in Europe, which produced rubber from marsh gas. I was fairly confident that its chemists, 
who could synthesize rubber from marsh gas, must be able to synthesize literally anything, and so I walked in with the connivance of the local chemical industries officer and asked them to produce some benzyl benzoate for me, which at that time was quite unknown in Germany. All I had in the way of literature was a National War Formulary and Mellanby's little monograph on Scabies. ${ }^{5}$ Of course, such local initiative was strictly against all regulations, but in those days of difficult communications one could take that risk.

The chemists did splendidly. The factory management was only too keen to manufacture anything which might justify a plea against dismantling their plant, now that they were prohibited from making their synthetic rubber. I got a good friend, the Regimental Medical Officer to the Glasgow Highlanders, to try the emulsion out on some of his Jocks, - agreed that their hide was not quite as sensitive as that of the German children, but it was the best I could do, for experimentation on Germans was quite out of question in those days of the Nuremberg trials. The M.O's report was satisfactory; the emulsion seemed at least as effective as the Army issue.

What to do next? To release the preparation into the chemists' shops would not have been satisfactory. A British-sponsored application might not then have gone down very well with the Germans and, in any case, self-application of any scabies application without the necessary public health measures, such as the concurrent examination and treatment of all household contacts, was doomed to failure. This much I had learned in the scabies clinic in Oxford.

I decided to set up a pioneer clinic in one of the Ruhr towns. As it was intended to be the precursor to similar clinics elsewhere, I avoided anything elaborate which might not be available everywhere. Baths were ruled out because of the fuel and soap shortage, and so was disinfestation of clothes and bedding, much to the horror of my German colleagues, who were not faniliar with Mellanby's findings. On the other hand, I laid great stress on a high standard of diagnosis, on thorough application of the emulsion, and on a complete follow-up of all household contacts. I was lucky to find a young skin specialist who had been in charge of the skin and V.D. wards of a Berlin Hospital and was now a farm worker. I got him to read up Mellanby and then put him in charge of the clinic which we staffed with Fürsorgerinnen, the German near-equivalent of health visitors, and with Red Cross nurses.

Our next problem was publicity. There were no papers in those days other than the weekly official gazette. Nor were there paper supplies for posters and handbills. So we got the school teachers to give all schoolchildren a dictation to take home, saying that an "itch clinic" was going to be opened in the Town Hall. We also had stills shown in the few cinemas which were open. The local M.O.H. addressed meetings of local doctors, a ticklish job, for he had to explain why we did not just make benzyl benzoate available to them all. I was opposed to this because I wanted the treatment to show its worth under controlled clinic conditions.

Publicity efforts soon proved unnecessary. The clinic publicised itself, and after a week or so we had to have police to control the queueing crowds, some of whom had come from far away. We only gave treatment when we could see the whole household, except that, after familiarising factory and mines' doctors and nurses with our routine, we let them do the men so that they lost no working time. 
Having proved the efficacy of our measure, we got in medical officers of health and health visitors from all other local authorities, talked to them, gave them a day in the clinic and let them have a translated abstract of Mellanby's work. Within a month from the start of our pioneer clinic we had at least one clinic working in every one of my 16 local government districts; in rural areas mobile teams did most of the work and even there despite the extreme reluctance of the Westphalian peasant ever to remove his clothes, the scheme was successful; the children, who were treated at school, acted as our propagandists.

Eight weeks after the first clinic had opened, weekly notifications had dropped from 2,000 to 150 . For once, one had been able to achieve something oneself, an impossibility with most of our major problems, such as housing, overcrowding, nutrition, etc., dependent as these were on high policy and massive resources. Incidentally, "Krätzemittel Harding ", the Harding scabies ointment, was on the point of being sold widely on a commercial basis, but this we managed to stop, though someone did acquire a German doctor's degree through a thesis with that title ${ }^{6}$.

I find that this " project" in the terminology of the Faculty of Community Medicine was conducted at just about the period during which the Community Medicine Trainee of today might enter the stage of higher specialist training. And I am afraid that my project would certainly not have passed today's Faculty examiners for Part II of the M.F.C.M., least of all my presidential predecessor; with no planned randomisation, when there was every opportunity for this to be done from the start, at least in academic theory, and with little by way of scientific evaluation.

But one lesson can be drawn from it for today: Community Medicine in the United Kingdom has derived much of its present status from outstanding pioneering by a relatively small number of distinguished academics. Now that it is being translated into a quite new service situation, and that the sky is the limit in terms of practical problems in the N.H.S. which need to be resolved, some opportunism seems not amiss in tackling tasks which can be resolved relatively quickly, and with a cost-effectiveness which can be clearly demonstrated.

It is tempting at this point to compare our most important long-term project of the period, about which I have spoken, the reorganisation of the German state health services, with the experience of the last two or three years in our National Health Service. Until not so long ago, I would have assessed the task and achievement of reorganising the largely destroyed or disrupted services of National Socialist Germany and their democratisation during the post-War period, which meant of course the inability to involve many of their most able people, as almost unsurpassable. But after two years in the reorganised National Health Service I see the Community Physician of today face an even more difficult task than the one with which we were faced thirty years or so ago, not merely because of the multiple tier structure, the incompatibility of N.H.S. and local authority structures, laborious consultation procedures and problems of consensus management if only because of the time these must take, but probably most important because few of us who are at present deployed in community medicine have been adequately and systematically trained for what is rightly described as an entirely new concept and commitment.

I recall the Faculty's definition of Community Medicine?: 
"Community Medicine is that medical speciality which deals with populations or groups rather than with individual patients. Therefore, in the context of a national system of health care it comprises those doctors who try to measure the needs of the population both sick and well, who plan and administer services to meet those needs and those who are engaged in research and teaching in the field ".

But history and the occasion demand that I follow with a quote from "A Scheme of Medical Tuition "9 which Parkes wrote 104 years before the Faculty was established and in which he contrasts Rumsey's ${ }^{8}$ somewhat legalistic concepts of State Medicine with his own so much wider outlook:

"The third subject is hygiene and State Medicine. Under the term of State medicine my friend Mr. Rumsey would include all medical matters which come before the law courts representing the State. This is no doubt logically correct, but there is, I think, a convenience in separating forensic cases, and in using the term State medicine as expressing all the relations between medical men and the State, except those which necessarily come before legal tribunals. If in the course of physiology and application of physiological truths to health were laid down -if, for example, the effect of diet, or exercise, of mental work, of habits, etc. on health had been there considered, the purely hygienic course might be short, and there would be time to consider the important topics of the health of communities, the action of laws and customs on them, the influence and regulation of trades, the care of the indigent sick, and such like topics, which form the domain of that part of State medicine which is not forensic.

It has taken even Parkes' own medical school not much less than a century to embark on such a teaching programme, but during the last few years we have seen nationally a definite upward trend in the teaching of community medicine, based on epidemiology, to undergraduates, though still with wide variations between medical schools. Concurrently the advent of the new Faculty has established community medicine in the reorganised N.H.S. as a medical discipline in its own right, practised by consultants in a non-hierarchical setting, in common with the clinical disciplines.

I find it difficult to judge whether the coincidence of the acceptance of the concept of community medicine and of the reorganised N.H.S. was an advantage or the opposite. It can be held that the approach of reorganisation was a necessary catalyst, and that only the union of hitherto divided hospital and public health services; - - let us face it that we have not yet achieved their organisational integration with gcneral practice;--could make a generic approach to community medicine possible.

On the other hand, the Faculty came into being too late to influence the new pattern of organisation, and the personal uprootings of practically all community physicians, and their redeployment into an entirely novel situation have severely impaired their intended constructive and forward looking role from the outset. We must give credit in this context to the central government departments for sponsoring crash training programmes through academic departments such as the Extension Centre of the London School of Hygiene, through which most of the now practising community physicians have acquired and continue to be offered some essential backing for their new function.

I consider the next few years as highly critical for the development and indeed survival of the new discipline. Clinicians, non-medical administrators, nurses and others have a right to ask to what extent our discipline is fulfilling its stated objectives. 
I have heard it argued that the severe financial cut-backs so soon after reorganisation may not only prevent or slow down the planned manpower build-up of community medicine, but actually lessen the need for community physicians, through the radical curtailment of capital programmes and revenue spending.

In my view this argument is not sound. By a manpower policy which has been evolved in consultations between the Departments of State in England and Wales, and the British Medical Association and the Faculty we have systematically assessed the need for posts in community medicine and released them against the availability of appropriately experienced and qualified manpower. The Faculty's nominees on appointment committees have been enjoined not to lower accepted standards in order to fill vacant posts. As a result several hundred less community physician posts have been released than had been occupied by medical hospital and public health administrators before reorganisation, and of these posts, between 700 and 750 in all, over 100 remain vacant.

It would be critical for the future of community medicine and indeed for the N.H.S. if there were cuts in the training programme or in the availability of posts available to those who reach specialist, that is, in civilian terms consultant status.

Certainly the Consultative Document on Priorities ${ }^{3}$ shows very clearly that financial restrictions demand a critical assessment of the present level of services at the local level, with a view to their possible redeployment to meet priority needs, or, in other words, quite simply a much greater emphasis on health care planning. This will require more rather than fewer community physicians, community physicians with an epidemiological approach who will become increasingly available as the postgraduate students in community medicine of today reach specialist status. As might be expected from the quality of their teaching, and here I must compliment this College on its increasing role in this sphere through its significant contribution to the teaching of students of the Thames Consortium, one is much impressed with the high quality of our postgraduate students. It would indeed be tragic if they were to be discouraged by a cut in the availability of posts, especially in health care planning in which few of the present community physicians have been systematically trained.

If planned reorientation of the N.H.S. to meet priority needs is our main objective, rather than the largely theoretic restructuring process which has been imposed upon us and the value of which is to say the least, doubtful, then community medicine can play a decisive part to this end. Sir John Richardson, formerly the Army's Consultant Physician and the first Chairman of the Armed Forces Medical Advisory Board, said recently ${ }^{10}$ : "The contribution of the Faculty is going to be literally enormous in the future, once you can get the quality of consultants within it that you so much desire. I feel very strongly that the scope for imagination, co-ordination, economy of resources, as well as most importantly the promotion of new ideas lies with your specialty really beyond any other."

The District Community Physician is probably the key figure in such a development. $\mathrm{He}$ is identified with the community served by the basic health service unit, and he should be seen by primary care and hospital clinicians as the colleague who can assist them with assessing the health care needs in the community they all serve and with the rational deployment of capital and revenue resources. Once his unbiased approach and 
his non-managerial role is recognised,-and we must accept that the ghosts of medical superintendents remain yet to be laid in certain hospitals, - the data which he can produce and interpret to clinical colleagues, to his administrative team and to the lay community will help increasingly towards rational policies in the allocation of resources within hospitals and between hospital and domiciliary and other field services.

At present he does so largely on an ad hoc basis and usually with little support in the collection and interpretation of essential statistics. This is why I have emphasized the need for health care planners to whom the District Community Physician can look for the necessary back up, from a higher administrative tier.

I select just one other from the large variety of community physicians in post in the National Health Service, eleven of them defined by D.H.S.S. and with many local variants, and find the emergence of the Specialist in Community Medicine (Social Services) of special interest at this stage. I have the impression that within a very short time these specialists have begun to bridge the chasm between the health and social services which was probably at its widest immediately before and after Seebohm. It seemed clear to many then, as it did 25 years earlier when Welfare and Health services were dealt with separately in the original Beveridge legislation, that with the biological indivisibility of human frailty, disability and handicap into medical and social components so radical an organisational segregation cannot be to the advantage of the individual and the community, though I fear that the medical profession must take much of the blame, through delaying overlong in accepting their colleagues in the emerging social services in a spirit of partnership. But it is little short of a paradox that, only a very few years after Seebohm, systems of joint planning and operating health and social services have now had to be created, and are to be supported by special funding to make them viable. We must hope that the new policy has not emerged entirely from financial stringency, but also from realisation of a functional need of integration. Here the contribution of the S.C.M. (Social Services) is vital. It is my impression that his or her non-hierarchical position outside local government-unlike that of the former Medical Officer of Health-is contributing to genuine co-operation in joint planning, though it is far too early to claim successes.

I cannot conclude a lecture to commemorate Edward Parkes without referring to Community Medicine in the setting of the Army. In its second report the so-called Edwards Committee ${ }^{11}$ recommended the recognition of the speciality in the Armed Services and the promotion of training for membership of the Faculty. I believe that for logistic reasons, but not least because of traditions inspired by pioneers such as Parkes, Pringle, and so many others, the Army will not find it difficult to adapt to the concept of Community Medicine which it is already practising to a large extent, also in training. I believe that plans for such a training programme and for the establishment of posts for higher postgraduate training are far advanced. Such posts will require recognition by the Faculty as in the civilian field. The question of providing for the Army trainees community health experience in a civilian setting, apart from attendance at academic courses, remains to be settled, but we in the Faculty tend to think that, provided a trainee is adequately trained to pass our generic Part I examination and completes his chosen project in Part II satisfactorily, up-to-date experience in the civilian health services is probably better offered in special training posts to those in the Services who seek a second career in community medicine at the time of their retirement. And here let 
me say that in my view those who can adapt easily - a potential which is built into any Service career-and can offer ten or even fewer years at the end of their service career will make a significant contribution to community medicine in the National Health Service, not just because of the shortage position which is not likely to be resolved in the foreseeable future, but because of their professional expertise, e.g. in medical staffing and organisation, and especially in environmental health.

Army medicine has always needed to concentrate on environmental health, Parkes' manual and other writings show this clearly-and much of their content remain valid today. The Army will always be in need of expertise on environmental health, and its medical staff will need to keep up-to-date in this sphere. In the National Health Service we already face problems through the organisational separation of environmental health from the National Health Service since reorganisation. I have no doubt whatsoever that the Services, and particularly the Army can make a significant contribution to N.H.S. in the training of the civilian community physician, and on this, as I have indicated, a start has already been made, possibly in the joint deployment of expertise between the Army and the N.H.S., and not least by the contribution of suitably experienced retired officers.

I have stressed my personal indebtedness to the Army for the experience of temporary service in the R.A.M.C. The vast majority of community physicians of my generation and of that which proceded it, and indeed of doctors of all kinds, have profited in a similar way, though few can have been as fortunate as I was. Crossfertilisation between the Services and the N.H.S. will become increasingly important in the future, when without conscription and, we hope, without wars comparatively few community physicians will have had the advantages of such direct involvement.

It is fitting to conclude with my earliest Parkes quote, from an Introductory Lecture in 1856 to students of University College ${ }^{12}$. He refers in it to Science as such, but you may agree that it is as relevant to Community Medicine, or perhaps to Service, Community and Health:-

"Fresh problems, fresh facts, fresh intricacies rise each day before the labourer, and demand enquiry, arrangement and elucidation. Invention and imagination are called into play; but at the same time the army of disciplined and orderly facts, the rank and file of scientific movement, are not abandoned or disarranged; impossible combinations are not attempted, and old positions, once fairly assumed, are not causelessly surrendered".

\section{BIBLIOGRAPHY}

PARKes, E. A. (1864). Manual of Practical Hygiene.

Prevention and Health, Everybody's Business (1970). London.

Priorities for Personal Health and Social Services in England (1976). London

PARKes, E. A. (1851). Introductory Lecture. Med. Tms (Lond.) 66, 343.

MellanBy, K. (1943). Scabies.

BuchHolz, F. G. (1947). Scabies und Scabies Behandlung. Münster University.

Faculty of Community Medicine (1976). Standing Orders. London.

Rumsey, H. W. (1856). Essays in State Medicine.

PARKES, E. A. (1868). A Scheme of Medical Tuition.

Richardson, Sir John (1976). (Personal communication).

Postgraduate Medical and Dental Education (1973). Second Report. June.

Parkes, E. A. (1858). On Self-Training by the Medical Student. 